\title{
Screening of High-Risk Pregnant Women for Thyroid Dysfunctions in a Moderately Mild lodine-Deficient Area
}

\author{
Imre Zoltán Kun, Zsuzsanna Szántó, Ildikó Kun and Béla Szabó
}

Additional information is available at the end of the chapter

http://dx.doi.org/10.5772/49971

\section{Introduction}

Pregnancy is a high risk condition for developing iodine-deficient disorders (IDD), mainly in circumstances of reduced iodine supply, due to the fact that during this physiological period of life the requirement of thyroid hormones increases with 30-50\% (Alexander et al., 2012, Leung et al. 2011). Besides goiter, thyroid dysfunctions may develop. When the compensatory mechanisms become insufficient subclinical or overt hypothyroidism occur. Hypothyroidism may cause maternal and fetal complications: miscarriage, abortion, premature delivery, birth complications, neonatal respiratory distress syndrome, intellectual disabilities in offsprings including cretinism, growth retardation (Boyages, 1993; Pharoah et al., 1971, de Escobar et al., 2007; Cao et al., 1994). Thus hypothyroidism must be recognized and treated as early as possible, which would be before pregnancy, to avoid the above mentioned complications. Screening of pregnant women and of those who intend to become pregnant would be an adequate method for this purpose.

However, the screening for thyroid diseases in pregnant and lactating women is still an issue under debate. The inclusion criteria of the screening process are mostly disputed. Some authors consider the screening of high-risk pregnant women for thyroid disorders sufficient, others suggest universal screening program (the assessment of all women during pregnancy for thyroid conditions), mostly in iodine deficient areas. Iodine and thyroid hormones are essential for normal fetal and neonatal development, and their increased requirement in pregnancy rises the frequency of goiter and thyroid dysfunctions. These diseases are often oligosymptomatic and can easily remain undiagnosed, consequently fetal developmental impairments of different severity (even mental retardation, endemic cretinism) can appear in the circumstances of iodine and thyroid hormone deficiency. 
Universal screening in pregnancy may be indicated in iodine deficient regions, but it represents a serious financial effort which was not considered justified by the evidences until 2007. Therefore, targeted case finding during early pregnancy, i.e. screening for thyroid diseases in high-risk pregnant women was recommended. This high-risk population group comprises pregnant women with history of hyper-/hypothyroidism, postpartum thyroiditis, thyroid surgery, previous head or neck radiation therapy, and miscarriage or preterm delivery, family history of thyroid disease, presence of goiter and/or thyroid antibodies, symptoms/clinical sings suggesting hyper-/hypothyroidism (including anemia, hypercholesterolemia, hyponatremia), type I diabetes and other autoimmune diseases (Endocrine Society's Clinical Guideline, 2007).

Iodine deficiency in Romania was confirmed by Milcu about 50-60 years ago (Milcu, 1956). The use of iodized alimentary salt has been introduced as a prophylactic method in our country since 1948 (15-25mg potassium iodide or 10mg potassium iodate per kg salt). From 1956 a supplementary iodine prophylaxis was started by administration of potassium iodide tablets (1mg KI/tb.) to school-age children and pregnant women.

The iodine status of our region, Mureş County, has been periodically assessed by a team of endocrinologists from the Endocrinology Clinic Târgu Mureş since 1960-70. From the geographic and epidemiologic point of view Mureş County is a 6,700 square km large hillymountainous region in the Transylvanian Basin, located in the centre of Romania, crossed by the river Mureş. Its estimated population is about 600,000 , with a light variation in the last decades: the number of inhabitants was 614,000 in 1984 , with a mild increase to 620,500 until 1990, followed by a slow decrease to 579,000 in 2007 . These data are provided by the epidemiologic registers of National Institute of Statistics based on the censuses of population and housing realized in Romania (Romanian National Institute of Statistics, 2012).

In 2000 Balázs et al. reported in a study the assessment of iodine deficiency in the hydrographic basin of the superior and middle part of river Mureş, including the collected data of 508 children in their work: $26.97 \%$ (137) from urban and $73.03 \%$ (371) from rural localities. The thyroid volume was evaluated clinically and ultrasonographically. The majority of rural localities presented mild and the others moderate iodine-deficiency. The county town, Târgu Mureş was found iodine-sufficient. The mean urinary iodine excretion was $100.22 \mu \mathrm{g} / \mathrm{L}$, but with large inter-individual variations (SD: \pm 73.37 ). This study emphasized the great frequency of small goiters in rural localities compared to their more reduced frequency in cities (Balázs et al., 2000/a).

Our studies performed during 2001-2004 (by the examination of urinary iodine content, thyroid ultrasound in school-age children and pregnant women, neonatal TSH screening) have confirmed that Mureş County was constantly a mild/moderate iodine deficient geographic area (Kun et al., 2003). During 2001-2003 we observed elevated serum TSHvalues (above $10 \mathrm{mIU} / \mathrm{L}$, according to the criterion of $\mathrm{WHO}$ ) in $8.23 \%$ out of 2,454 studied newborns, with a mean TSH-level of $19.81 \pm 12.63 \mathrm{mIU} / \mathrm{L}$ (Szántó et al., 2007). 
According to these data is obvious that Mureş County, during the last decades of $20^{\text {th }}$ century and beginning of the $21^{\text {st }}$ century was characterized as a moderate/mild iodine deficient area, thus an extensive screening of thyroid disturbances in pregnant women could be indicated, but it was not performed for financial reasons. In these circumstances we started a targeted screening in pregnant women with history of thyroid diseases and gestational complications (previous miscarriage, preterm or post-term delivery, postpartum anemia), as well as suggestive clinical signs/symptoms for thyroid dysfunctions.

Extended studies realized during 2002-2004 have shown a moderate iodine deficiency in the majority (80\%) of Romanian counties (mainly in rural areas), the prevalence of endemic goiter being between $0-40 \%$ and low urinary iodine excretion at $2 / 3$ in the examined persons (Simescu et al., 2006).

In order to ameliorate this national endemic problem a Romanian governmental decision (no. 568/5 June 2002) regarding the universal alimentary salt-iodization decided the release of alimentary salt with increased iodine-content on the market $\left(34 \pm 8.5 \mathrm{mg} \mathrm{KIO}_{3} / \mathrm{kg}\right)$. This Decision was implemented into practice in December 2003, and in 2004 the mandatory use of iodized salt in baking industry was disposed in all 41 counties, both in households and bakeries (Second National Conference for the Elimination of Iodine Deficiency Disorders, 2005; Kun, 2006). Consequently, iodized salt was used in $96 \%$ of households in 2004, according to some authors (Simescu et al., 2006). At the same time, starting from 2002 a national program has begun in order to estimate the iodine status of the Romanian population by promulgating IDD screening programs in high risk population groups (newborns, school-children, pregnant women). After the implementation of universal saltiodization the incidence of IDD has decreased considerably in school-children in several counties (Simescu et al., 2006).

After these legislative changes, during 2004-2006 we restarted neonatal screening for thyroid dysfunctions. Comparing screening data obtained before and after universal salt iodization (2001-2003 vs. 2004-2006) we did not find significant differences regarding the incidence of elevated TSH levels, but an important reduction of mean values was observed in the second period $(15.63 \pm 7.35 \mathrm{mIU} / \mathrm{L})$ compared to the first one $(19.81 \pm 12.63 \mathrm{mIU} / \mathrm{L}$, i.e. a decrease with $4.2 \mathrm{mIU} / \mathrm{L}, \mathrm{p}=0.02$ ), pleading for the amelioration of iodine deficiency (Kun, 2006; Kun et al., 2007).

In 2005-2006 the assessment of iodine status in three mountain villages showed a significant improvement of urinary iodine excretion (UIE) compared to data published by Balázs et al. (2000/b): in 1999 UIE was $56.00 \pm 38.07 \mu \mathrm{g} / \mathrm{L}$, being normal only in $6 \%$ of the investigated children, mild (50-99 $\mu \mathrm{g} / \mathrm{L})$ and moderately low $(20-49 \mu \mathrm{g} / \mathrm{L})$ each in $44 \%$, and under $20 \mu \mathrm{g} / \mathrm{L}$ (very low) in 6\%. Our results in October 2006 were improved, but still subnormal: the mean UIE increased to $85.37 \pm 60.05 \mu \mathrm{g} / \mathrm{L}, 30.8 \%$ of the children had normal values, and iodinedeficiency related hypothyroidism had an incidence of $15 \%$ in the investigated schoolchildren. Thyroid ultrasound performed in these children showed diffuse goiter in $27 \%$ of the cases. Rural mountain areas of Mureş County known before as moderate/mild iodine 
deficient zones have become mild-deficient ones, due to the new measures of iodine prophylaxis (Kun et al., 2007).

According to our previous studies Mureş County was considered a moderate/mild iodinedeficient area before 2003, and based on our new results this area still may be considered a mild iodine-deficient region, mainly in mountainous rural localities (Kun, 2006; Kun et al., 2007; Balázs et al., 2000/b; Szántó et al., 2007), and thus iodine-prophylaxis has an important role in preventing IDD and its complications, including thyroid dysfunctions.

The main cause of iodine deficiency in most rural localities of Mureş County is their localization on hilly-mountainous geographical regions, composition of the land and water (Mureş river and its affluents) having low iodine content. The geographical isolation of mountainous places could be involved to some extent, the more isolated a locality is the more severe the iodine deficiency is. Larger localities and cities, such as Târgu Mureş were iodine sufficient places.

The evaluation of thyroid status in pregnant women living in Mureş County has not been reported yet, although our targeted screening started in 2001. We consider targeted screening for thyroid dysfunctions in pregnant women the thyroid assessment of those subjects who had thyroid disease or gestational complications in the past or who recently have developed signs/symptoms of thyroid dysfunction or goiter during pregnancy - so we consider these pregnant women of high risk.

\section{Objectives}

We proposed to perform the screening of thyroid dysfunctions in pregnant women residents of Mureş County, being at high risk for these diseases, by determining the frequency and severity of hypo-/hyperthyroidism and the possible related gestational complications.

We also wanted to assess the influence of universal salt iodization on thyroid status of this population group by comparing the results of targeted screening of high-risk pregnant women realized before (2001-2003) and after (2004-2006) taking effect the governmental Decision 568/2002, starting from December 2003.

\section{Material and methods}

Material. During November 2001 - February 2003 we performed a targeted screening of thyroid dysfunctions in 321 pregnant women living in Mureş County. This screening meant that TSH- and $\mathrm{FT}_{4}$-levels were measured in pregnant women with history of thyroid disease, clinical signs or symptoms suggestive for thyroid dysfunction or goiter, history of gestational complications (threatened abortion, abortion, imminent preterm birth, preterm delivery, miscarriage) or complications during current pregnancy. These inclusion criteria implied that subjects with history of thyroid condition and gestational complications firstly underwent endocrinological evaluation mainly in the first trimester, but others were screened when one of the mentioned criteria appeared, which could happen in any trimester, even in the third one. 
These pregnant women were registered in endocrine out-patient units from Târgu Mureş, Sighişoara, Reghin and Târnăveni (all four cities of our county), as well as in the Obstetrics \& Gynecology Clinics in Târgu Mureş (the main city of Mureş County). In some cases we determined the titer of thyroid peroxidase antibodies (TPO-Ab) and urinary iodine excretion, too.

In order to evaluate the influence of universal iodization of alimentary salt on thyroid function in pregnancy, starting from 2004 we performed a second targeted screening based on the same inclusion criteria. Thus, during February 2004-September 2006 we screened 206 pregnant women, then we compared the results with those obtained during 2001-2003.

Gestational complications were assessed according to data provided by out-patient Endocrinology units, and medical records of pregnant women hospitalized for gestational complications or for delivery in the Obstetrics \& Gynecology Clinics from Târgu Mureş, or obstetrical and neonatal sections of Hospitals from Sighişoara, Reghin and Târnăveni.

The state of health of newborns to hypothyroid mothers was evaluated in the first 5 days of their life, and the distribution of neonatal complications were assessed. These data were compared to a group of neonates born from apparently healthy mothers: normal TSH-level (between 1.5-2.5mIU/L), absence of thyroid diseases and other gestational risk factors (Rhincompatibility, twin pregnancy, smoking etc.).

Since 2007 a new large systematized screening of pregnant women has not been performed yet, further investigations being necessary depending on financial possibilities.

Methods. Serum thyrotropin (TSH) and free-thyroxine $\left(\mathrm{FT}_{4}\right)$ levels were measured from venous blood during the morning in all women included in the study. Third generation immunometric assay (ECLIA - electrochemiluminescence immunoassay) was applied at the Central Laboratory of Emergency Clinical Hospital Mureş County.

Until 2006 we considered the reference range for TSH-level 0.2-3.5mIU/L in the first and 0.4$4.0 \mathrm{mIU} / \mathrm{L}$ in the second and third trimesters and in case of pathological levels we started specific treatment, but in 2006-2007 new normal TSH-values for pregnant women were adopted (Endocrine Society's Clinical Guideline, 2007) and according to these we have reevaluated our data base.

Reference ranges for serum TSH-levels were adjusted for pregnant women according to the gestational trimester: between $0.03-2.5 \mathrm{mIU} / \mathrm{L}$ during the I., between $0.1-3.1 \mathrm{mIU} / \mathrm{L}$ in the II. and between $0.1-3.5 \mathrm{mIU} / \mathrm{L}$ in the III. trimester.

$\mathrm{FT}_{4}$ reference range is $0.86-1.86 \mathrm{ng} / \mathrm{dL}$ in the first and $0.64-1.92 \mathrm{ng} / \mathrm{dL}$ in the II.-III. trimesters.

We also assessed isolated maternal hypothyroxinaemia, which was considered by us as a reduced $\mathrm{FT}_{4}$ along a normal TSH level. This definition is not well delineated in the literature, because the reference range of TSH-level varies between large limits according to different authors and the gestational trimester (Vaidya et al., 2012; Glinoer \& Abalovich, 2007; Burman, 2009). We have evaluated the TSH- and FT $_{4}$-values based on the above mentioned normal intervals. 
The titer of TPO-Ab was considered normal under $35 \mathrm{IU} / \mathrm{mL}$. We could measure this parameter randomly in a total of 46 pregnant women from the whole casuistry: 24 cases during 2001-2003 and 22 during 2004-2006.

Urinary iodine excretion (UIE) measured with a semiquantitative rapid test was included into three ranges: $<10 \mu \mathrm{g} \%$, between $10-30 \mu \mathrm{g} \%$ and $>30 \mu \mathrm{g} \%$, values $<30 \mu \mathrm{g} \%$ are considered low. This was determined in 69 randomized cases: 34 pregnant women included in the first and 35 in the second period.

The obtained data were statistically evaluated by Students' " $\mathrm{t}^{\prime \prime}$ test and $\chi^{2}$ test. The difference between parameters of two groups was considered significant, if $\mathrm{P}$-value $<0.05$.

Ethical considerations: Every pregnant woman was informed about screening procedures, the benefit of hormonal assessment, possible side effects and than the hormonal results. In case of thyroid dysfunction specific endocrine treatment was performed. The Research Ethics Committee of the University of Medicine and Pharmacy Târgu Mureş has approved the outline of the research process and the obtained results for publication, as all ethical rules were respected.

\section{Results}

During November 2001-February 2003, before the implementation of the presented governmental decision about universal alimentary salt-iodization we screened 321 high-risk pregnant women: $263(81.9 \%)$ were euthyroid, 51 (15.88\%) hypothyroid and $7(2.18 \%)$ hyperthyroid. Two third (34 cases) out of the investigated hypothyroid women had subclinical and one third (17 cases) overt form. Among the 7 hyperthyroid pregnant women 4 suffered of subclinical and 3 of overt form.

\begin{tabular}{|c|c|c|c|c|}
\hline Trimester & Total cases & Hypothyroidism & Goiter* & Hyperthyroidism \\
\hline I. & 102 & $23(22.5 \%)$ & $41(40.2 \%)$ & $2(1.96 \%)$ \\
\hline II. & 126 & $15(11.9 \%)$ & $53(42.0 \%)$ & $1(0.79 \%)$ \\
\hline III. & 93 & $13(13.9 \%)$ & $48(51.6 \%)$ & $4(4.3 \%)$ \\
\hline Total & 321 & $51(15.88 \%)$ & $142(44.23 \%)$ & $7(2.18 \%)$ \\
\hline
\end{tabular}

Table 1. Thyroid state of pregnant women being in different gestational trimesters (2001-2003)

${ }^{*}$ I. grade diffuse goiter in $>80 \%$, II. grade goiter in $14.4 \%$, III. grade goiter in $0.6 \%$ of women.

Only $31.8 \%$ of the subjects were screened in the first trimester, the others were detected later (39.2\% in the II. and $29 \%$ in the III. trimester).

We could follow-up 28 hypothyroid pregnant women having thyroid hypofunction from the inclusion in the screening until delivery. Half of them presented gestational complications: 2 threatened abortions, one imminent preterm delivery, 5 preterm births, 2 prolonged deliveries, 2 caesarean sections for fearing fetal asphyxia, one miscarriage (hypertension, edema) and one pre-eclampsia. In four patients other gestational risk factors could contribute to the development of these complications (Rh-incompatibility, twin pregnancy, smoking). 
We excluded these cases, so the rate of gestational complications in hypothyroid pregnant women without other apparent risk factors decreased to $45.8 \%(11 / 24)$.

\begin{tabular}{|c|c|c|c|c|}
\hline $\begin{array}{c}\text { Gestational } \\
\text { age at } \\
\text { delivery }\end{array}$ & & Newborns of hypothyroid mothers & & $\begin{array}{l}\text { borns of apparently } \\
\text { healthy mothers }\end{array}$ \\
\hline \multirow{4}{*}{ preterm } & \multirow{4}{*}{5} & 2 clinically healthy & \multirow{4}{*}{2} & \multirow{2}{*}{1 clinically healthy } \\
\hline & & 1 preterm - premature grade II. & & \\
\hline & & 1 preterm - premature grade I., $A=7 / 1^{\prime}$ & & \multirow{2}{*}{1 asphyxia, $A=7 / 1^{\prime}$} \\
\hline & & 1 death by severe asphyxia* & & \\
\hline \multirow{2}{*}{ post-term } & \multirow{2}{*}{2} & 1 clinically healthy & \multirow{2}{*}{\multicolumn{2}{|c|}{-}} \\
\hline & & 1 asphyxia, $\mathrm{A}=8 / 1^{\prime}$ & & \\
\hline \multirow[b]{2}{*}{ born at term } & \multirow[b]{2}{*}{21} & 20 clinically healthy & \multirow[b]{2}{*}{24} & 23 clinically healthy \\
\hline & & $\begin{array}{l}1 \text { asphyxia, } A=8 / 1^{\prime} \text { (thyroidectomized } \\
\text { mother, subclinical hypothyroidism) }\end{array}$ & & 1 asphyxia, $A=7 / 1^{\prime}$ \\
\hline Total & 28 & & 26 & \\
\hline
\end{tabular}

Table 2. Newborns' health status at delivery and on the first 5 days of life A: Apgar score; case marked with * is presented in the text

Seven (25\%) out of the 28 neonates from hypothyroid mothers were born preterm or postterm, while $2(7.7 \%)$ out of 26 apparently healthy women gave birth to preterm newborn. We observed preterm or post-term delivery in hypothyroid pregnant women significantly more often than in apparently healthy women (P-value: 0.07, OR: 3.7, 95\%CI: 0.86-5.91), although these cases of hypothyroidism were mainly subclinical forms.

In one woman diagnosed with Hashimoto's thyroiditis in the third trimester multiple complications have developed: late miscarriage, severe pre-eclampsia, grade II. uteroplacental apoplexia, which needed caesarean section at the 32-33. gestational week. The newborn (case marked with * in Table 2.) presented acute fetal suffering (Apgar score 1/1', $\left.2 / 5^{\prime}, 3 / 10^{\prime}\right)$. The newborn died on the $14^{\text {th }}$ day of life due to severe asphyxia during birth, hyaline membrane disease, persistent pulmonary hypertension and pneumonia.

One pregnant woman with overt hyperthyroidism out of the total 7 hyperthyroid cases during 2001-2003 developed imminent premature birth.

TPO-Ab determined in 24 randomized cases was elevated in 3 patients (12.5\%).

During November 2001 - February 2002 urinary iodine excretion measured with semiquantitative method in 35 pregnant women showed values above $30 \mu \mathrm{g} \%$ in $11.4 \%$, between $10-30 \mu \mathrm{g} \%$ in $20 \%$ and $<10 \mu \mathrm{g} \%$ in $68.6 \%$ out of the total investigated women. Thus, UIE was subnormal in $88.6 \%$ of the cases.

During February 2004-September 2006, after the legislative changes regarding universal iodine prophylaxis took effect we screened 206 pregnant women, their hormone status being presented in Table 3. 


\begin{tabular}{|c|c|c|c|c|c|}
\hline \multirow{2}{*}{ Thyroid function } & \multirow{2}{*}{ No. cases } & \multirow{2}{*}{$\%$} & \multicolumn{3}{|c|}{ Trimester } \\
\cline { 4 - 6 } & & & I. & II. & III. \\
\hline hypothyroidism & 20 & 9.7 & $13.8 \%$ & $8.1 \%$ & $11.9 \%$ \\
\hline hyperthyroidism & 6 & 2.9 & $5.8 \%$ & $4.3 \%$ & $0 \%$ \\
\hline euthyroid state & 180 & 87.4 & & & \\
\hline Total & 206 & \multicolumn{4}{|l}{} \\
\hline
\end{tabular}

Table 3. Thyroid function of 206 high-risk pregnant women screened during 2004-2006

Out of the 20 hypothyroid pregnant women 12 (60\%) had subclinical and 8 (40\%) overt hypofunction. Out of the 6 thyrotoxic pregnant women 4 had overt and the other 2 subclinical disease.

The titer of TPO-Abs determined only in 22 women was normal in all cases. Urinary iodine excretion measured in 34 pregnant women detected iodine deficiency in $84.2 \%$ of these cases.

Half of the pregnant women with hypothyroidism detected by targeted screening during 2004-2006 suffered from gestational complications: 5 imminent abortions, 2 imminent premature births, 3 miscarriages. One woman with thyroid cancer treated before pregnancy by thyroidectomy and insufficient substitutive-suppressive $\mathrm{T}_{4}$-therapy presented imminent abortion (the case was included into the previously mentioned complications).

Three pregnant women out of the 6 hyperthyroid cases developed imminent abortion, hyperemesis gravidarum and imminent premature birth. All 3 had overt thyrotoxicosis (the majority of overt forms).

\begin{tabular}{|c|c|c|c|}
\hline Thyroid dysfunction & $\mathbf{2 0 0 1 - 2 0 0 3}$ & $\mathbf{2 0 0 4 - 2 0 0 6}$ & P-value \\
\hline Hypothyroidism & $\begin{array}{c}51 \text { cases }-15.88 \% \\
\text { (3 post-thyroidectomy) }\end{array}$ & $\begin{array}{c}20 \text { cases }-9.7 \% \\
\text { (1 PTC, thyroidectomy) }\end{array}$ & 0.049 \\
\hline $\begin{array}{c}\text { Overt/Subclinical } \\
\text { hypothyroidism }\end{array}$ & $17: 34(=1: 2)$ & $8: 12(=2: 3)$ & 0.081 \\
\hline Hyperthyroidism & 7 cases $-2.18 \%$ & 6 cases $-2.91 \%$ & 0.44 \\
\hline $\begin{array}{c}\text { Overt/Subclinical } \\
\text { hyperthyroidism }\end{array}$ & $3: 4$ & $2: 1$ & \\
\hline
\end{tabular}

Table 4. Comparison of data obtained during 2001-2003 and 2004-2006

PTC: papillary thyroid carcinoma

During 2004-2006 the frequency of hypothyroidism in pregnant women has decreased significantly (with about 40\%) compared to the previous period (2001-2003), but the ratio of overt/subclinical forms remained almost the same. The proportion of complications in hypothyroid women was similar in the two studied periods, but the total number of cases decreased in the second interval so the absolute number of gestational complications among pregnant women was reduced in the second period. Targeted case finding screening could 
identify high-risk pregnant women in the first trimester only in $1 / 3$ of the cases, the others being detected later.

The rate of hyperthyroidism showed mild increase, which proved to be non-significant compared to 2001-2003. All hyperthyroid pregnant women with gestational complications suffered from overt hyperthyroidism.

Finally we evaluated a very controversial problem: the isolated maternal hypothyroxinaemia. This means a low free- $\mathrm{T}_{4}$ concentration along a normal TSH-level. In our group we observed a few women suffering from such condition, and we considered them patients who need thyroid hormone replacement therapy.

During 2001-2003 a number of 8 (2.96\%) cases had isolated hypothyroxinaemia among the 270 pregnant women with normal TSH-value: 2 in the first trimester (mean TSH: $1.10 \pm$ $0.66 \mathrm{mIU} / \mathrm{L}$, mean FT4: $0.69 \pm 0.08 \mathrm{ng} / \mathrm{dL}$ ), 3 in the second (mean TSH: $1.39 \pm 0.41 \mathrm{mIU} / \mathrm{L}$, mean $\mathrm{FT}_{4}: 0.61 \pm 0.02 \mathrm{ng} / \mathrm{dL}$ ), and 3 in the third trimester (mean TSH: $2.8 \pm 0.34 \mathrm{mIU} / \mathrm{L}$, mean FT: $0.58 \pm 0.06 \mathrm{ng} / \mathrm{dL})$.

During 2004-2006 only two (1.1\%) pregnant women in the third trimester presented low $\mathrm{FT}_{4}$ among the 182 subjects with normal thyrotropin (mean TSH: $1.68 \mathrm{mIU} / \mathrm{L}$, mean $\mathrm{FT}_{4}$ : $0.63 \mathrm{ng} / \mathrm{dL})$.

Thus, among the total number of 527 pregnant women $1.89 \%$ had isolated hypothyroxinaemia, mainly in the third trimester (half of the cases), when the upper normal limit of TSH-level is extended to 3.5mIU/L. In these latter cases the TSH-levels were situated mainly between 2.8-3.2 approaching to the upper normal limit in the III. trimester.

\section{Discussion}

During pregnancy the iodine requirement is increased by different mechanisms. One of these is the increase of maternal thyroxine secretion to maintain euthyroidism: the elevated TBG-level due to hyperestrogenism binds $\mathrm{T}_{4}$ in higher amounts as in non-pregnant conditions and must be saturated to obtain normal free thyroid hormone levels. At the same time, a part of iodine and maternal thyroid hormones are transferred to the fetus, particularly in later gestation. The other cause is the secretion of placental hCG (human chorionic gonadotropin), which stimulates thyroid hormone secretion (similarly with TSH) mainly near the end of the first trimester, and thus it can be associated with a transient lowering in serum TSH (Glinoer, 1999). Finally, a presumed cause of increased iodine requirement is the augmented renal iodine clearance in pregnancy (see Tabel 5).

The iodine and the thyroid hormones are essential for the normal general development of offspring, especially for the differentiation of CNS, being indispensable for neuronal migration, arborization of dendrites, myelination of axons, normal synaptogenesis, synaptic transmission and plasticity during fetal and early postnatal life. The increased iodine and thyroid hormone requirement during pregnancy favours the development of iodinedeficiency disorders (IDD) and of subsequent hypothyroidism, having serious consequences 
on both maternal and fetal organisms, especially in conditions of reduced iodine supply in endemic regions.

\begin{tabular}{|l|l|}
\hline Causes & Consequences \\
\hline Hyperestrogenism & $\begin{array}{l}\text { elevated TBG-level and increased binding of } \\
\text { thyroid hormones: for maintenance of } \\
\text { euthyroidism maternal thyroxine secretion must be } \\
\text { augmented }\end{array}$ \\
\hline Placental hCG & stimulates the thyroid hormone secretion \\
\hline Transplacental transfer & $\begin{array}{l}\text { primarily in the first trimester and in fetal } \\
\text { hypothyroidism }\end{array}$ \\
\hline Increased renal iodine clearance & urinary iodine losing \\
\hline
\end{tabular}

Table 5. The causes of increased iodine requirement in pregnancy

Iodine deficiency is still a health problem, not only worldwide but also in Europe. Recent French data show that in Northern Paris area the mean UIE was low $(49.8 \mu \mathrm{g} / \mathrm{L})$, far under $100 \mu \mathrm{g} / \mathrm{L}$, the formerly considered normal value (Luton et al., 2011). Taking into account that WHO currently recommends a median UIE in pregnant women of $150-249 \mu \mathrm{g} / \mathrm{L}$, this result is still more alarming. Similarly, in the Lyon metropolitan area Raverot et al. (2012) found that pregnant women are iodine-deficient, $77 \%$ of them having a median UIE under $150 \mu \mathrm{g} / \mathrm{L}$.

In countries or regions where under $90 \%$ of households are using iodized salt and the median UIE in school-age children is under $100 \mu \mathrm{g} / \mathrm{L}$, WHO recommends iodine supplementation during pregnancy and infancy. Recently, WHO/UNICEF/ICCIDD increased the Recommended Nutrient Intake for iodine during pregnancy from 200 to $250 \mu$ g/day and considered that the adequate iodine intake is reflected by a median UIE of $150-249 \mu \mathrm{g} / \mathrm{L}$ (Zimmermann, 2009). In lactating women and children under the age of 2 years a median UIE of $100 \mu \mathrm{g} / \mathrm{L}$ can be used to define adequate iodine intake; although lactating women have the same requirement as pregnant women, the median urinary iodine is lower because iodine is also excreted in breast milk (WHO, 2007, see Table 6).

\begin{tabular}{|c|c|c|}
\hline $\begin{array}{c}\text { Iodine dose } \\
(\mu \mathrm{g} / \mathrm{day})\end{array}$ & Organization and date & $\begin{array}{c}\text { Median urinary iodine excretion } \\
(\text { median UIE } \mu \mathrm{g} / \mathrm{L})\end{array}$ \\
\hline 200 & $\begin{array}{c}\text { World Health Organization 1994; } \\
\text { WHO/NUT/94.6,Geneva }\end{array}$ & 100 \\
\hline 250 & WHO/UNICEF/ICCIDD 2007 & $150-249$ \\
\hline
\end{tabular}

Table 6. The evolution of recommended iodine intake during pregnancy

WHO: World Health Organization; UNICEF: United Nations Children's Fund; ICCIDD: International Council for the Control of Iodine Deficiency Disorders

In lactating women and children under the age of 2 years a median UIE of $100 \mu \mathrm{g} / \mathrm{L}$ indicates adequate iodine intake; although lactating and pregnant women have the same iodine requirement, in formers the median UIE is lower due to iodine excretion in breast milk (WHO, 1994; 2007). 
It is well known, that in severe iodine deficient regions maternal and fetal hypothyroidism can cause classic or masked cretinism or reduces cognitive development in children; to prevent fetal damage, iodine should be given before or in early pregnancy. During the 1st trimester, the fetus is completely dependent upon the thyroxine produced by the mother (Springer et al., 2011).

A new USA trial has shown that when a hypothyroid woman becomes pregnant, she should immediately increase her levothyroxine dose by two tablets per week in order to remain biochemically euthyroid. This protocol significantly reduces the risk of maternal hypothyroidism during the first trimester and mimics normal physiology (Alexander et al., 2004; Reuters Health Information 2010). It was previously reported that $\mathrm{T}_{4}$ requirement may rise as early as the fifth week of gestation (Alexander et al., 2004). In general, pregnant women started this protocol at a median of 5.5 weeks of pregnancy. Other authors recommended for women who became pregnant to increase the dose of levothyroxine by 30 $50 \%$. Several authors would first check thyroid function tests before adjusting the dose (Vaidya et al., 2012). Thyroid hormone levels must be monitored at least every 4 week until $20^{\text {th }}$ weeks, because the required doses of $\mathrm{T}_{4}$ increase during pregnancy. The recommended control of thyroid hormone levels only at the $30^{\text {th }}$ weeks of pregnancy may be considered insufficient, because in $92 \%$ of the cases were detected abnormal TSH values (Alexander et al., 2004; Reuters Health Information 2010).

Our study shows that the targeted screening of high-risk pregnant women for thyroid dysfunctions according to the before mentioned inclusion criteria resulted the inclusion into the screening of only about $1 / 3$ of pregnant women in the first gestational trimester (31.8\% - 102 subjects from the 321 cases during 2001-2003), the others being detected only in the second or third trimester $(39.2 \%$ in the II. and $29 \%$ in the III. trimester) according to symptoms, signs and/or gestational complications developed later during pregnancy.

Early maternal iodine deficiency and hypothyroidism may cause developmental impairments in the fetal nervous system, but evidences about the consequences of later (after the first trimester) initiated thyroid hormone replacement therapy and of mild-tomoderate iodine deficient maternal status are still limited. It is not clarified whether this mild maternal iodine deficiency can influence, and if so in what extent the cognitive function of offsprings. Studies showed impaired intellectual and motor development in children from endemic areas, but presumably other factors could affect mental development, too (Zimmermann, 2009).

Taking into account that under the circumstances of targeted screening in high-risk pregnant women a large number of subjects are screened later, after the first gestational trimester, it is recommended to start thyroid hormone replacement as soon as possible. Thus the tendency to perform universal screening in early pregnancy for thyroid conditions, first of all in iodine deficient regions is justifiable. 
Aggressive thyroid hormone replacement before or in early pregnancy is justified, but to recommend or discuss the possibility of therapeutic abortion in case of initiation the substitutive hormone therapy after the first trimester, because of fearing evident cognitive delay in offsprings, is not warranted (Downing et al., 2012). A quarter of the European thyroidologists recently responding to the electronic questionnaire survey of Vaidya et al. proved to have this opinion. In case of fetal hypothyroxinaemia it must be taken into account that there are also compensatory mechanisms that favour the transfer of thyroid hormones through placenta into the fetus. In this respect, it can be mentioned that according to a study the IQ of children born from mothers diagnosed with hypothyroidism during early pregnancy was normal, similarly to children born from mothers without thyroid hypofunction (Liu et al., 1994).

The iodine state of a geographical area can be quantified by more indicators. Besides the screening of pregnant women using $\mathrm{TSH}$ and/or $\mathrm{FT}_{4}, \mathrm{TPO}-\mathrm{Ab}$ assays, the serum TSH concentration in neonates measured in blood collected between the $3^{\text {rd }}$ and $7^{\text {th }}$ days of life is another indirect indicator. The incidence of cases with neonatal serum TSH $>10 \mathrm{mIU} / \mathrm{L}$ reflects the grade of iodine deficiency: between 3-19.9\% indicates moderate, between 20$39.9 \%$ severe and $>40 \%$ very serious iodine deficiency (WHO, 1994; Delange, 1998). A frequency under $3 \%$ of TSH $>5 \mathrm{mIU} / \mathrm{L}$ indicates iodine sufficiency.

We obtained in the studied periods TSH $>10 \mathrm{mIU} / \mathrm{L}$ in $8-9 \%$ of newborns, indicating moderate iodine deficiency in Mureş County (Szántó et al., 2007).

Other laboratory and imagistic parameters are urinary iodine excretion and thyroid ultrasound effectuated in school-children and pregnant women.

The increased iodine and thyroid hormone requirement during pregnancy favours the development of hypothyroidism with consequences on both maternal and fetal organisms, and this may be aggravated in iodine deficient endemic regions. Since iodine deficiency is a continuous health problem worldwide, and knowing our region as a hilly-mountainous one, we have started to evaluate the iodine status of our county in the mirror of the criteria for iodine deficiency estimation (WHO, 1994). The studies realized on neonates and school-aged children cohorts have demonstrated that during 1990-2003 Mureş County was a moderately mild iodine deficient area (Kun et al., 2003; 2007; Kun, 2006) in the condition of relatively systematic iodine prophylaxis, but not rigorously controlled by legislative means. In that period of time iodized alimentary salt contained about $16 \mathrm{mg}$ KI per $\mathrm{kg}$, and it was not mandatory to sell on market exclusively iodized alimentary salt. Simultaneously we started to evaluate pregnant women known with previous or present thyroid conditions and gestational complications, without the possibility of screening all pregnant women. Although, in recent recommendations living in an area with iodine insufficiency represents a risk factor for thyroid disorders in pregnant women (StagnaroGreen et al., 2011), so our endemic region represents increased risk factor during pregnancy. 
In our study the rate of hypothyroidism in pregnant women with history of thyroid conditions or gestational complications, as well as signs/symptoms of thyroid dysfunction was $15.88 \%$ during 2001-2003, subclinical forms being diagnosed in 2/3 of cases. Gestational goiter was present in average $44.2 \%$ of the cohort and the randomly measured UIE showed reduced values in the majority of cases $(88.6 \%)$, that suggest the insufficient prophylactic effect of the used iodized alimentary salt at that time (mean $16 \mathrm{mg} \mathrm{KI} / \mathrm{kg}$ salt). A proportion of $2.18 \%$ of high-risk pregnant women had hyperthyroidism. According to reported data thyroid dysfunction is observed in about $10 \%(0.4-25 \%)$ of pregnant women, its frequency being dependent on the severity of iodine-deficiency and the presence of thyroid antibodies.

Our targeted screening of high-risk pregnant women has detected mainly subclinical hypothyroidism in the circumstances of moderately mild iodine deficiency before 2003. This mild form of thyroid dysfunction develops due to increased requirement of iodine and thyroid hormones during pregnancy and/or due to iodine deficiency and autoimmune lymphocytic thyroiditis (Badenhoop, 2000; Hehrmann, 2002). Anyway, the prevalence of Hashimoto's thyroiditis in pregnancy is low, about 0.8-1\% (Badenhoop, 2000), but it can increase during iodine prophylaxis, and this disease can also provoke gestational complications without any thyroid dysfunction (Negro et al., 2007; Thangaratinam et al., 2011). In our cohort severe maternal and fetal complications developed in one case of chronic autoimmune thyroiditis and mild hypothyroidism, but we suppose that other factors might also contribute to this severe case of miscarriage (e.g. immunologic ones), taking into account that the grade of maternal hypothyroidism was mild.

Neonates born to hypothyroid mothers presented almost significantly higher frequency of pre- or post-term delivery in comparison with the control group (newborns of apparently healthy mothers) $-25 \%$ vs. $7.7 \%$.

The screening and treatment of subclinical hypothyroidism in pregnancy have been recommended since 2001-2002 (Mann, 2001; Hehrmann, 2002), after the recognition of its role in development of maternal and fetal complications. Although subclinical hypothyroidism is a very mild thyroid dysfunction, it can favour both gestational/delivery and fetal complications (delay of central nervous system development and consecutive mental retardation). According to data reported by Abalovich in 2002 the frequency of both abortion and premature birth in inadequately treated pregnant woman with overt hypothyroidism was high $(60 \%$ and $20 \%$, respectively), but, surprisingly, the frequency of abortion in subclinical forms was much higher (above 70\%). The rate of premature birth was $7 \%$ in case of subclinical hypothyroidism. Under the condition of adequate $\mathrm{T}_{4}$-substitution of overt hypothyroidism $100 \%$, but in state of subclinical form about $90 \%$ of pregnant women had normal termed delivery (Abalovich et al., 2002). Several studies showed that pregnancy was more likely to be complicated if subclinical hypothyroidism was present (Casey et al., 2005; Pop et al., 2003).

Other studies showed, that in course of pregnancy, the outcome of delivery and postpartum period, the neuromuscular development of newborns is mainly dependent on TPO-Ab level. 
In pregnant women the frequency of increased TPO antibodies is about 9\% (Hehrmann, 2002). During 2001-2003 we could determine in our targeted screening the TPO-Ab-level in only 24 pregnant women, and we obtained elevated levels in 3 women. One of these three cases was diagnosed with Hashimoto-thyroiditis in the III. trimester, she developed high blood pressure, oedema, pre-eclampsia and premature birth, the new-born presenting severe asphyxia and died after birth. Data in the literature showed that from the second trimester onward, the major adverse obstetrical outcome associated with raised TSH was the increased rate of fetal death (Allan et al., 2000). The reduced number of TPO-Ab-positive cases in our cohort may be explained by immunsuppression during pregnancy: in the first trimester the level of antithyroid antibodies can increase, but after that TPO-Ab-level may decrease to the normal level until delivery.

Iodine and thyroid hormone deficiency in the first trimester inhibits the development of the nervous system in the fetus, because the fetal organism is unable to produce sufficient amounts of thyroid hormones. Iodine deficiency in the precocious period of pregnancy conducts to the most severe neural impairments (mental retardation, dwarfism, neuromuscular complications, as spastic paresis of the limbs). These complications are irreversible, thus their prevention is indispensable. Later (II.-III. trimesters) may appear growth disturbances, but these are not irreversible.

As our results show, during 2001-2003 the frequency of goiter increased gradually with gestational trimester. In the I. and II. trimester $40.2 \%$ and $42.1 \%$ of pregnant women had goiter, respectively, and this rate increased to $51.6 \%$ in the III. trimester. These results show indirectly the endemic character of our geographical area.

After 2002, when the government decree took effect, universal iodine prophylaxis was applied with an increased iodine content alimentary salt $(34 \pm 5 \mathrm{mg} / \mathrm{kg})$ and a more stable iodine salt $\left(\mathrm{KIO}_{3}\right)$. Our targeted screening to detect thyroid dysfunction in pregnant women showed a decreasing tendency in the frequency of hypothyroidism (9.7\%, P:0.049), being significantly reduced compared to the first period $(15.88 \%)$, although, the distribution according to severity remained practically identical (subclinical forms in $50 \%$ vs. $40 \%$ in the first and second studied period of time). The ratio of overt:subclinical hypothyroidism remains almost unchanged during the two studied periods (1:2 vs. 2:3). The values of urinary iodine excretion of the two intervals did not differ significantly, in concordance with the similar data obtained in the whole country in 2004.

Conversely, the frequency of hyperthyroidism had a slightly increasing tendency after universal iodine prophylaxis, but this change was not significant (2.18\% in 2001-2003 vs. $2.91 \%$ in 2004-2006). According to the literature the prevalence of hyperthyroidism in the United States is about $1 \%$. The distribution of clinical and subclinical forms is almost equal: $0.4 \%$ overt and $0.6 \%$ subclinical forms. The activity level of autoimmune thyroid diseases may fluctuate during gestation, with exacerbation during the first trimester and gradual improvement during the later gestational period (The Endocrine Society's 
Clinical Guideline, 2007). Graves' disease accounts for about $85 \%$ of hyperthyroidism during pregnancy. In autoimmune thyroiditis a hyperthyroid phase of Hashimoto's thyroiditis and silent thyroiditis may occur. The risk of complications for both mother and fetus is related to the duration and control of maternal hyperthyroidism. Inadequately treated maternal thyrotoxicosis is associated with increased risk of preterm delivery, which can occur in up to $88 \%$ of these pregnant women (The Endocrine Society's Clinical Guideline, 2007).

Iodine prophylaxis is needed in all pregnant women, not only for those living in endemic regions. In euthyroid (normal TSH-level), TPO-Ab-negative pregnant women without goiter, iodine usually must be applied in doses of $200-260 \mu g /$ day. The use of iodine supplementation is also indicated in cases of elevated TPO-Ab-level, primarily for the fetus. We should also inform pregnant women that iodine overdose can induce hypothyroidism, so for detection repeated laboratory investigations may be necessary. This statement is also valid for the lactation period.

In the treatment of endemic goiter, the increased need for iodine and thyroid hormones for both pregnant and fetus requires iodine administration (in the before mentioned doses) with or without association of $\mathrm{T}_{4}$-treatment (e.g. in doses of $50-75 \mu \mathrm{g} / \mathrm{day}$ ), the later alone being not sufficient during pregnancy.

We must emphasize that in the II. trimester, the $\mathrm{T}_{4}$-level decreases and the $\mathrm{TSH}$ and the $\mathrm{T}_{3} / \mathrm{T}_{4}$ ratio increase in one third of pregnant women. In this situation we must increase the $T_{4}$ dose individually (but avoid the suppression of TSH). Generally, an adequate treatment of hypothyroidism needs increasing $\mathrm{T}_{4}$ doses as pregnancy progress. Thus, in early pregnancy we must monitor the thyroid hormone and TSH-levels frequently (e.g. on 10 days interval at the beginning, after that every 3-4 weeks during the first half of pregnancy, and monthly or every 6 weeks during the second half), to administer T4-preparations properly, in increasing doses.

At the same time during pregnancy and lactation smoking and all medications with inhibitory effect on the thyroid function must be avoided. Among these iodine excess (iodinated contrast materials, amiodarone) must be emphasized. Iodine excess can induce not only hypothyroidism (through Wolff-Chaikoff effect), but also thyrotoxicosis (hyperthyroidism or subacute thyroiditis). These dysfunctions may appear both in mother and offspring (fetuses and neonates). The appearance of these adverse reactions depend on several factors, among them the iodine dose is very important. In this respect Kochi et al. (2012) show that there was no significant adverse clinical reaction of thyroid function abnormalities in the fetus after administering iv. iodinated contrast material to the mothers for computed tomography scan. In contrast, radioiodine administration is strictly contraindicated for both diagnostic and therapeutic purposes in pregnant women, because it can destroy the offspring's thyroid function. This rule is also valid in case of the thyroid cancer. When thyroid cancer is diagnosed during pregnancy, a decision must be taken 
regarding performing thyroidectomy during the pregnancy or postponing surgical resection until the postpartum period. Radioactive iodine is absolutely contraindicated during pregnancy and lactation (Yazbeck \& Sullivan, 2012).

Isolated maternal hypothyroxinemia may have negative effects on motor, cognitive and neurobehavioural performance of the offspring, taking into account that maternal thyroxine plays a pivote role upon the normal nervous system development of the fetus. Screening of pregnant women for thyroid dysfunctions firstly measures TSH-levels, while free- $\mathrm{T}_{4}$ assays have limitations in clinical use. In these situations isolated maternal hypothyroxinemia may not be detected.

The frequency of isolated maternal hypothyroxinemia and its impact on maternal/fetal complications, as well as therapeutical recommendations are not clarified entirely, yet. The incidence of this special hormonal state during pregnancy varies among wide intervals, depending on the iodine status of the geographical area, the trimester-specific hormonal assays and the used normal ranges, thus according to these influencing factors published data showed an incidence ranging between 1.3-26.5\% (Casey et al., 2007; Vaidya et al., 2007; Clear-Goldman et al., 2008; Berbel et al., 2009; Moleti et al., 2009; Shan et al. 2009; Hendrichs et al., 2010). The prevalence is the lowest in the first gestational trimester (1.2-3.2\%) but than it starts to increase gradually during the II. and III. trimesters reaching values as high as $26.5 \%$ (Berbel et al., 2009). The true incidence of isolated maternal hypothyroxinemia is not known, yet.

The influence of this state on pregnancy outcome and on fetal development is a question under debate. Some researchers have stated that isolated maternal hypothyroxinemia has no influence on obstetrical adverse outcomes (Casey et al., 2007), but further investigations in this respect are needed. It was reported, that isolated maternal hypothyroxinemia is associated with impaired neurodevelopment of offsprings (Pop et al., 1999), but this must also be confirmed by further surveys.

The etiology of this state is also not known exactly. It was reported that in the circumstances of short-term iodine prophylaxis the prevalence of isolated hypothyroxinemia is 5-fold higher than in pregnant women who had regularly used iodized salt for at least 2 years before pregnancy occurred (36.8\% versus 6.4\%) (Moleti et al., 2011). It was suggested, that the cause of isolated hypothyroxinemia is iodine deficiency instead of autoimmune thyroid processes, such as among 56/220 (25.4\%) pregnant women with isolated hypothyroxinemia $\mathrm{TPO}-\mathrm{Ab}$ were detectable in only $7.1 \%$ of them (Moleti et al., 2009). Data published so far are not sufficient to recommend thyroxine replacement therapy in this case in pregnancy, although a study analysing questionnaires about the treatment of hypothyroidism during pregnancy filled in by over 600 members of the European Thyroid Society (ETA) showed that $38 \%$ of the responders would treat isolated maternal hypothyroxinemia, but the responders' definition of this disorder was not consistent (Vaidya et al., 2012), which reflects the lack of clear definition and management of this state. 


\section{Conclusions}

During 2001-2003 the frequency of hypothyroidism in high-risk pregnant women was $15.88 \%$ in Mureş County, a region with moderately mild iodine deficiency, the subclinical forms predominate versus overt hypothyroidism. During 2004-2006, after the implementation in practice of universal salt-iodization and more rigorous follow-up of thyroid dysfunctions the frequency of hypothyroidism in pregnancy decreased significantly (to $9.7 \%$ ). Complications (imminent abortion, premature birth, gestational hypertension, pre-eclampsia) appeared with high frequency (in 50\%) among hypothyroid pregnant women in the two periods of time. Special measures of iodine-prophylaxis are necessary in case of every pregnant woman, mainly for those living in endemic regions, because the universal salt-iodization (in our region iodized alimentary salt with $34 \pm 8.5 \mathrm{mg} / \mathrm{kg} \mathrm{KIO}_{3}$ ) is not sufficient in all cases. Targeted screening could identify high-risk pregnant women in the first trimester only in $1 / 3$ of cases, the others being detected later. Thus, our results plead for the necessity of universal screening of pregnant women for thyroid dysfunctions and their regular follow-up even in a mild iodine deficient area, taking into account that iodine deficiency, primarily through inducing hypothyroidism, can have detrimental effects on fetal brain development even from the first gestational trimester. Similarly, the early recognition and adequate treatment of thyroid disorders can contribute substantially to decrease of frequency and severity of other maternal and fetal complications related to these dysfunctions.

\section{Author details}

Imre Zoltán Kun and Ildikó Kun

University of Medicine and Pharmacy, Târgu Mureş,

Mureş County Clinical Hospital, Endocrinology Clinic, Târgu Mureş,

Romania

Zsuzsanna Szántó

University of Medicine and Pharmacy, Târgu Mureş,

Romania

Béla Szabó

University of Medicine and Pharmacy, Târgu Mureş,

Clinic of Obstetrics E Gynecology No. 1., Târgu Mureş,

Romania

\section{Acknowledgement}

The authors are grateful to the Sapientia Foundation from Cluj-Napoca, Romania for its financial contribution in supporting the costs of hormonal measurements. The authors express their gratitude to Győrfi Annamária for her collaboration in the translating process of this text. 


\section{References}

Abalovich M, Gutierrez S, Alcaraz G, Maccallini G, Garcia A, Levalle O (2002) Overt and subclinical hypothyroidism complicating pregnancy. Thyroid 12/1: 63-68.

Alexander EK, Marqusee E, Lawrence J, Jarolim P, Fischer GA, Larsen PR (2004) Timing and magnitude of increases in levothyroxine requirements during pregnancy in women with hypothyroidism. New Engl J Med 351: 241-249. (doi:10.1056/NEJMoa 040079).

Allan WC, Haddow JE, Palomaki GE, Williams JR, Mitchell ML, Hermos RJ, Faix JD, Klein RZ (2000) Maternal thyroid deficiency and pregnancy complications: implications for population screening. J Med Screen 7: 127-130.

Badenhoop K (2000) Hashimoto-Thyreoiditis in der Schwangerschaft. In: Derwahl, K.M.Heufelder, AE editors. Endokrine Erkrankungen während der Schwangerschaft und Postpartalphase. Berlin, Blackwell Wissenschafts Verlag. Pp. 68-72.

Balázs J, Kun IZ, Buksa C, Coroş L, Vasilescu G, Năsălean A (2000/a) Study of endemic goiter, chronic thyroiditis, thyroid function in corelation with iodine intake at school-children living in the superior and middle hydrographic basin of the river Mureş [in Romanian] Revista de Medicină şi Farmacie Targu Mureş 46: 240244.

Balázs J, Pintea A, Buksa C, Vasilescu G (2000/b) The thyroid volume and the iodine intake in school-children from Târgu-Mureş [in Romanian]. Revista de Medicină şi Farmacie Targu Mureş 46: 60-63.

Berbel P, Mestre JL, Santamaria A, Palazon I, Franco A, Graells M, Gonzales-Torga A, de Escobar GM (2009) Delayed neurobehavioral development in children born to pregnant women with mild hypothyroxinemia during the first month of gestation: the importance of early iodine supplementaion. Thyroid 19/5: 511-519.

Boyages SC (1993) Clinical review: iodine deficiency disorders. J Clin Endocrinol Metab. 1993; 77/3: 587-591

Burman KD (2009) Controversies surrounding pregnancy, maternal thyroid status, and fetal outcome. Thyroid 19: 323-326.

Cao XY, Jiang XM, Dou ZH, Rakeman MA, Zhang ML, O’Donnell K, Ma T, Amette K, DeLong N, DeLong GR (1994) Timing of vulnerability of the brain to iodine deficiency in endemic cretenism. N Eng J Med 331/26: 1739-1744.

Casey B, Dashe JS, Wells CE, McIntire DD, Byrd W, Leveno KJ, Cunningham FG (2005) Subclinical hypothyroidism and pregnancy outcome. Ostet Gynecol 105: 239-245.

Casey BM, Dashe JS, Spong CY, McIntire DD, Leveno KJ, Cunningham GF (2007) Perinatal significance of isolated maternal hypothyroxinemia identified in the first half of pregnancy. Obstet Gynecol 109(5): 1129-1135.

Cleary-Goldman J, Malone FD, Lambert-Messerlian G, Sullivan L, Canick J, Porter TF, Luthy D, Gross S, Bianchi DW, D'Alton ME (2008) Maternal thyroid hypofunction and pregnancy outcome. Obstet Gynecol 112/1: 85-92. 
de Escobar GM, Obregon MJ, del Rey FE (2007) Iodine deficiency and brain development in the first half of pregnancy. Public Health Nutr 10/12A: 1554-1570

Delange F (1998) Screening for congenital hypothyroidism used as an indicator of IDD control. In: Pinchera A, Mann K, Hostalek U editors. The Thyroid and Age, Merck European Thyroid Symposium Italy, April 30-May 2, 1998. Stuttgart: Schattauer Verlagsgesellschaft mbH. pp. 121-134.

Downing SD, Halpern L, Carswell J, Brown RS (2012) Severe Early Maternal Hypothyroidism Corrected Prior to the Third Trimester Associated with Normal Cognitive Outcome in the Offspring. Thyroid, 2012 Mar 7.

Glinoer D (1999) What happens to the normal thyroid during pregnancy? Thyroid 9(7): 631635.

Glinoer D, Abalovich M (2007) Unresolved questions in managing hypothyroidism during pregnancy. BMJ 335: 300-302.

Henrichs J, Bongers-Schokking JJ, Schenk JJ, Ghassabian A, Schmidt HG, Visser TJ, Hooijkaas $\mathrm{H}$, de Muinck Keizer-Schrama SM,Hofman A, Jaddoe VV, Visser W, Steegers EA, Verhulst FC, de Rijke YB, Tiemeier H (2010) Maternal thyroid function during early pregnancy and cognitive functioning in early childhood: the generation $R$ study. J Clin Endocr Metab 95/9: 4227-4234.

Hehrmann R (2002) Immunthyreopathien in der Schwangerschaft - Auswirkungen auf den Fetus. In: Mann K, Weinheimer B, Janßen OE editor. Schilddrüse und Autoimmunität. Berlin, Walter de Gruyter GmbH \& Co. KG. pp. 284-294.

Kochi MH, Kaloudis EV, Ahmed W, Moore WH (2012) Effect of in utero exposure of iodinated intravenous contrast on neonatal thyroid function. J Comput Assist Tomogr 36/2:165-169.

Kun I (2006) Hypothyroidism in Mureş County - Doctoral thesis. [in Romanian: Insuficiența tirodiană în județul Mureş], University of Medicine and Pharmacy Târgu Mureş.

Kun IZ, Szántó Zs (2003) The frequency and complications of hypothyroidism in Mureş County - [in Hungarian: A pajzsmirigyelégtelenség és szövődményeinek gyakorisága Maros megye területén]. In: Brassai A editor. Orvostudományi Tanulmányok Sapientia Könyvek. Scientia Cluj-Napoca, pp. 131-206.

Kun IZ, Balázs J, Năsălean A, Gliga C, Deteşan G, Simescu M, Coroş L, Ionescu A, Madaras G, Szántó Zs, Macarie C (2007) Iodine deficiency detected through urinary iodine excretion in school-children living in goiter prevalent regions of County Mureş (20052006). 9th European Congress of Endocrinology Budapest, 28 April - 2 May 2007, Budapest. Endocrine Abstracts. 14: P353.

Leung AM, Pearce EN, Braverman LE (2011) Iodine nutrition in pregnancy and lactation. Endocrinol Metab Clin North Am 40/4: 765-777.

Liu H, Momotani N, Noh JY, Ishikawa N, Takebe K, Ito K (1994) Maternal hypothyroidism during early pregnancy and intellectual development of the progeny. Arch Intern Med 154: 785-787. (doi:10.1001/archinte.154.7.785) 
Luton D, C Alberti, E Vuillard, G Ducarme, JF Oury, J Guibourdenche (2011) Iodine Deficiency in Northern Paris Area: Impact on Fetal Thyroid Mensuration. PLoS ONE 6(2): e14707, doi:10.1371/journal.pone.0014707.

Mann K (2001) Latente Schilddrüsenfunktionsstörungen - Welche Diagnostik, welche Therapie? In: Hensen J, Allolio B, Grußendorf M et alii editors. VI. Intensivkurs für Klinische Endokrinologie, 24.-27. Oktober 2001, Hannover. pp. 209-218.

Milcu SM (1956) Guşa endemică [in Romanian] - Editura Academiei Republicii Populare Române, Bucharest.

Moleti M, Lo Presti VP, Mattina F, Mancuso A, De Vivo A, Giorgianni G, Di Bella B, Trimarchi F, Vermiqlio F (2009) Gestational thyroid function abnormalities in conditions of mild iodine deficiency: early screening versus continuous monitoring of maternal thyroid status. Eur J Endocrinol 160/4: 611-617.

Moleti M, Di Bella B, Giorgianni G, Mancuso A, De Vivo A, Alibrandi A, Trimarchi F, Vermiglio F (2011) Maternal thyroid function in different conditions of iodine nutrition in pregnant women exposed to mild-moderate iodine deficiency: An observational study. Clin Endocrinol 74/6: 762-768.

Negro R, Formoso G, Coppola L, Presicce G, Mangieri T, Pezzarossa A, Dazzi D (2007) Euthyroid women with autoimmune disease undergoing assisted reproduction technologies: the role of autoimmunity and thyroid function. J Endocrinol Invest 30(1): 3-8.

Pharoah PO, Butterfield IH, Hetzel BS (1971) Neurological damage to the fetus resulting from severe iodine deficiency during pregnancy. Lancet 1:308-310.

Pop VJ, Kuijpens JL, van Baar AL, Verkerk G, van Son MM, de Vijlder JJ, Vulsma T, Wiersinga WM, Drexhage HA. Vader HL (1999) Low maternal free thyroxine concentrations during early pregnancy are associated with impaired psychomotor development in infancy. Clin Endocrinol 50: 149-155.

Pop V, Brouwers EP, Vader HL, Vulsma T, Van Baar AL, De Vijlder JJ. (2003) Maternal hypothyroximaemia during early pregnancy and subsequent child development: a 3year follow-up study. Clin Endocrinol (Oxf) 59: 282-288.

Raverot V, Bournaud C, Sassolas G, Orgiazzi JJ, Claustrat F, Gaucherand P, Mellier G, Claustrat B, Borson-Chazot F, Zimmermann M (2012) French pregnant women in the Lyon area are iodine deficient and have elevated serum thyroglobulin concentrations. Thyroid 2012 Feb 23.

Shan ZY, Chen YY, Teng WP, Yu XH, Li CY, Zhou WW, Gao B, Zhou JR, Ding B, Ma Y, Wu Y, Liu Q, Xu H, Liu W, Li J, Wang WW, Li YB,Fan CL, Wang H, Guo R, Zhang HM (2009) A study for maternal thyroid hormone deficiency during the first half of pregnancy in China. Eur J Clin Invest 39/1: 37-42.

Simescu M, Dimitriu L, Sava M, Chiovernache D, Colda A, Balmes E, Ursu H, Bistriceanu M, Zosin I, Duncea I, Balazs J, Kun IZ, Dragatoiu G, Hazi G, Coamesu I, Harsan T, Stamoran L, Florescu E, Vitiuc M, Varciu M, Budura I, Fugaciu A, Hutanu T, Lepadatu D, Sulac H, Munteanu M, Parlog L, Podia Igna C, Sirbu A (2006) Urinary iodine levels 
in schoolchildren and pregnant women after the legislative changes in the salt iodization. Acta Endocrinol (Buc) 2(1): 33-44.

Springer D, Limanova Z, Zima T (2011) Thyroid in Pregnancy. In: Fulya Akin editor. Basic and Clinical Endocrinology Up-to-Date. Rijeka: Intech. pp. 37-50.

Stagnaro-Green A, Abalovich M, Alexander E, Azizi F, Mestman J, Negro R, Nixon A, Pearce EN, Soldin OP, Sullivan S, Wiersinga W (2011) Guidelines of the American Thyroid Association for the diagnosis and management of thyroid disease during pregnancy and postpartum. Thyroid 21: 1081-1125

Szántó Zs, Kun I, Kun IZ, Coroş L, Cucerea M (2007) The influence of universal salt iodization on the iodine status reflected by TSH serum levels of newborns, in Mureş County, between years 2001-2006. Acta Endocrinol (Buc) III(3): 291-301.

Thangaratinam S, Tan A, Knox E, Kilby MD, Franklyn J, Coomarasamy A. (2011) Association between thyroid autoantibodies and miscarriage and preterm birth: metaanalysis of evidence. BMJ 9: 42: d2616. doi: 10.1136/bmj.d2616.

Vaidya B, Anthony S, Bilous M, Shields B, Drury J, Hutchison S, Bilous R (2007) Brief report: detection of thyroid dysfunction in early pregnancy: universal screening or targeted high-risk case finding?" J Clin Endocrinol Metab 92/1: 203-207.

Vaidya B, Hubalewska-Dydejczyk A, Laurberg P, Negro R, Vermiglio F, Poppe K (2012) Treatment and screening of hypothyroidism in pregnancy: results of a European survey. Eur J Endocrinol 166(1): 49-54.

Yazbeck CF, Sullivan SD (2012) Thyroid disorders during pregnancy. Med Clin North Am 96(2): 235-256.

Zimmermann MB (2009) Iodine deficiency in pregnancy and the effects of maternal iodine supplementation on the offspring: a review. Am J Clin Nutr 89(2): 668S-72S.

The Endocrine Society's Clinical Guideline (2007) Management of Thyroid Dysfunction during Pregnancy and Postpartum: An Endocrine Society Clinical Practice Guideline. J Clin Endocrinol Metab 92/8: 12-31.

The Second National Conference for the elimination of Iodine Deficiency Disorders (IDD) (2005) The National Strategy to eliminate the iodine deficiency disturbances by the universal salt iodization in alimentary and bakery industry 2004-2012. Bucharest, 14 November 2005:3-12. Abstracts on CD.

Reuters Health Information (2010) Hypothyroid Women in 1st Trimester Need 2 Extra Levothyroxine Pills/week. J Clin Endocrinol Metab http://jcem.endojournals.org/cgi/ cn tent/abstract/jc.2010-0013v1

Romanian National Institute of Statistics. Censuses of Population and Housing, http://www.recensamantromania.ro

World Health Organization, United Nations Children's Fund, International Council for Control of Iodine Deficiency Disorders (1994) Indicators for assessing Iodine Deficiency Disorders and their control through salt iodization. WHO/NUT/94.6,Geneva: World Health Organization 1994 pp. 1-55. 
World Health Organization. United Nations Children's Fund \& International Council for the Control of Iodine Deficiency Disorders (2007) Assessment of iodine deficiency disorders and monitoring their elimination. 2nd ed. Geneva, Switzerland: WHO. 